\title{
An Automated Range-animal Data Acquisition System
}

\author{
D.C. ADAMS, P.O. CURRIE, B.W. KNAPP, T. MAUNEY, AND D. RICHARDSON
}

\begin{abstract}
An automated range-animal data acquisition system (ARADS) has been developed to collect individual animal data without human intervention. Records include date, time, identification, live-weight, water consumption, and weather variables. The system is presently being used to monitor free-ranging yearling steers and mature cows. ARADS is composed of 7 portable scale units, a weather station, and a central computer all linked together through a radio communication network. The system is expandable to include additional data stations and parameters, and the number of animals identified is not limited by the system. Scale units and the weather station operate in extreme temperatures $\left(40\right.$ to $\left.-40^{\circ} \mathrm{C}\right)$, precipitation and wind.
\end{abstract}

Key Words: free ranging cattle, live weight, water consumption, range, electronic animal identification, sampling methods

Cattle foraging on Northern Great Plains rangelands are subjected to a harsh environment due to wide fluctuations in forage and weather conditions. The chemical composition of range plants varies with season (Cogswell and Kamstra 1976) and weather. These variables also affect time budgets and performance of range cattle (Adams et al. 1986). Continuous live-weight and weather data are needed to evaluate forage and environmental interactions in order to optimize biologically sound cattle management strategies and range improvement practices. Frequent movement and handling of cattle for conventional weighing are impractical because they may alter performance and/or disrupt normal activity of the animal (Adams 1985). Time and labor requirements are also costly. Thus, automating data acquisition would appear likely to enhance data accuracy and reduce stress to both researcher and animal. Marten et al. (1967) made an early attempt to automatically weigh free-ranging cattle. However, it was not until electronic identification was coupled to automatic weighing that monitoring free-ranging individual animals became a reality (Anderson et al. 1981). The following description details an automated rangeanimal data acquisition system (ARADS) ${ }^{1}$ developed to allow continuous collection of animal performance data in several plots

Authors are range nutritionist, range scientist, statistician, USDA Agricultural Research Service at Fort Keogh Livestock and Range Research Station, Route I, Box 2021, Miles City, Mont. 59301; and scientist and president of GeoResearch, Inc., 2815 Montana Avenue, Billings, Mont. 59101.

This paper is a contribution from the U.S. Department of Agriculture, Agricultural Research Service, and Montana Agriculture Experiment Station, Miles City, Mont., Journal Serics No. J1858.

Manuscript accepted 23 October 1986. under range conditions with minimal animal disturbance and labor input.

\section{System Description}

ARADS has 3 basic components: (1) 7 portable electronic scales, (2) a stationary weather station, and (3) a main station central computer all linked together via a radio communication network (Fig. 1). Each component operates independently except when data transfer or control changes are required. Animals enter the scale units on a free-choice basis to gain access to drinking water. Therefore, water from other sources must be restricted at each study site to ensure that data will be collected. Water under pressure is metered into self-filling water bowls by electronic flow meters to determine consumption. Each scale is equipped with an electronic animal identification interrogator which recognizes individual transponders attached to the ear of each animal (Fig. 2). The identification transponders are encapsulated in plastic discs approximately $30 \mathrm{~mm} \times 8 \mathrm{~mm}$ weighing $10 \mathrm{~g}$. The discs are attached to the ear by commonly available plastic ear tag buttons with inserting pliers. Billions of individual transponders identification codes are possible. Live weight is measured at the times an animal enters and exits the scale. The difference between entry and exit weights provides a cross check on water consumption measurements. The scale is zeroed automatically when empty after recording the live weight of each animal. The time and date of each measurement event are also recorded, allowing utilization of the data in behavioral investigations.

Individual animals enter and exit from the rear of the scale. To prevent animals outside of the scale from perturbing weights, the scale is enclosed by panels on the front and sides and is equipped with an air-powered gate at the rear which closes behind each animal. This ensures that only one animal is weighed at a time (Fig. 3 and 4). Photocells determine when the gates should open and close and initiate the measurement cycle.

Scale units are portable between fall-winter and spring-summer grazing locations. Each study site has $\mathrm{AC}$ power and a pressurized water supply. The scale unit is leveled and securely fastened to a concrete pad before data collection. The microprocessor scale controllers are housed in weatherproof enclosures and include

IARADS was developed in cooperation with GeoResearch, Inc., Billings, Mont. 59101 under USDA-ARS Contract 54-3K06-50. These systems are now manufactured by GeoResearch, Inc. with the trade name READS (Remote Electronic Animal Data Systems). Use of this system does not constitute endorsement by the U.S. Department of Agriculture to the exclusion of other systems. 


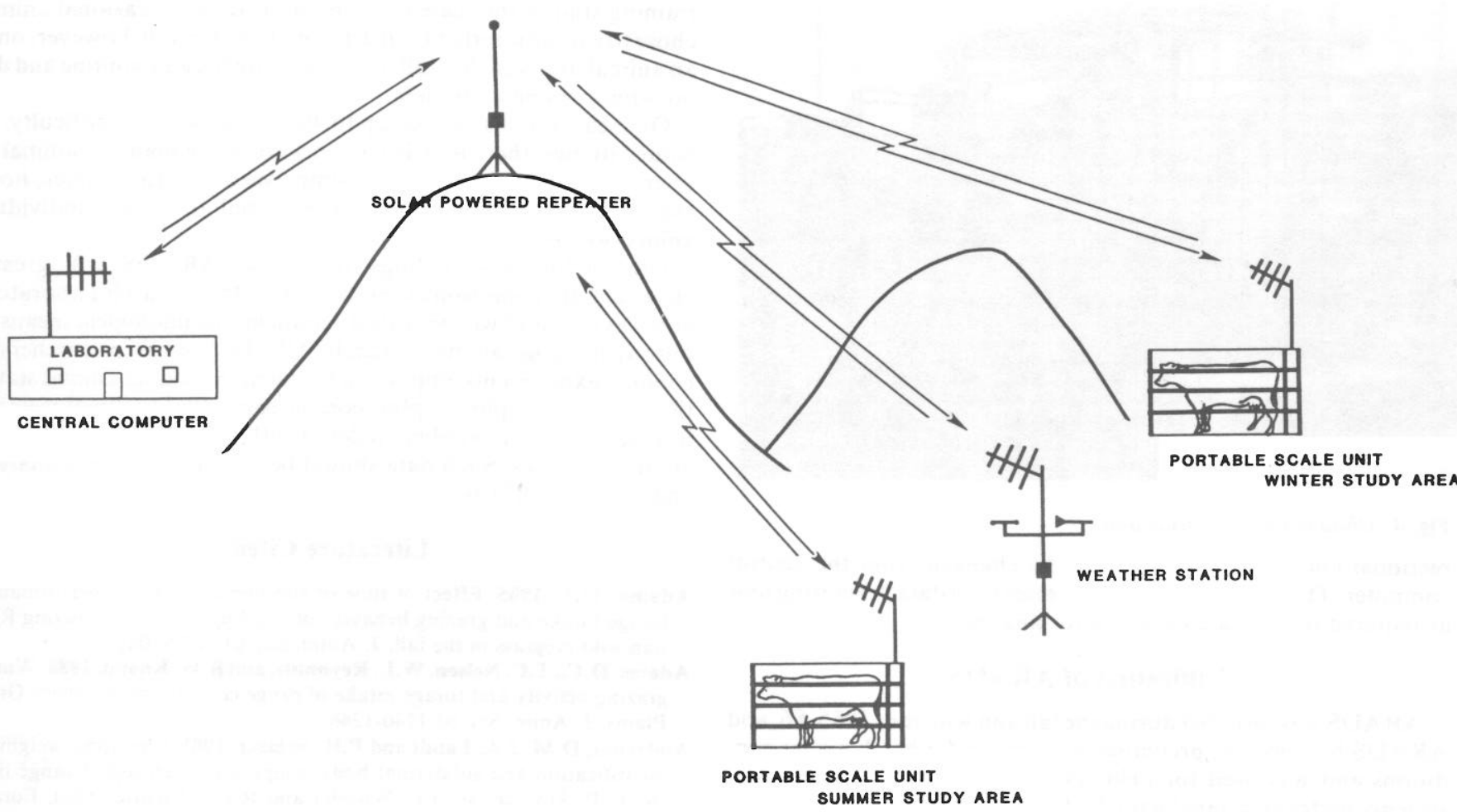

Fig. 1. Schematic of the automated range-animal data acquisition system.

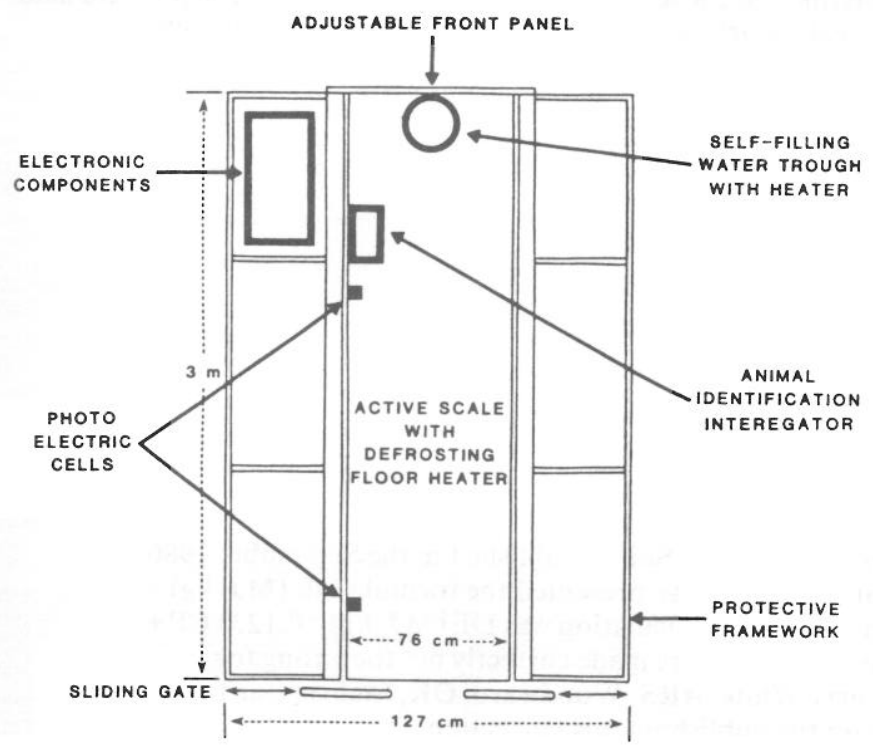

Fig. 2. Diagram of scale unit, top view.

backup batteries to prevent data loss during AC power interruptions. Load cells on the scales are mounted overhead to keep the load cells clear of mud and snow. Scale decks are equipped with electrical heating elements so that ice and snow building can be removed as needed. During winter, water in each water bowl is heated to $1-2^{\circ} \mathrm{C}$ to prevent freezing, and the water pipes drain in the event of power failure. The maximum length of each weighing platform is $3 \mathrm{~m}$, but the length can be shortened for smaller animals by moving the water unit toward the back of the scale. Additional analog channels, RS-232 ports, and storage can be added to the

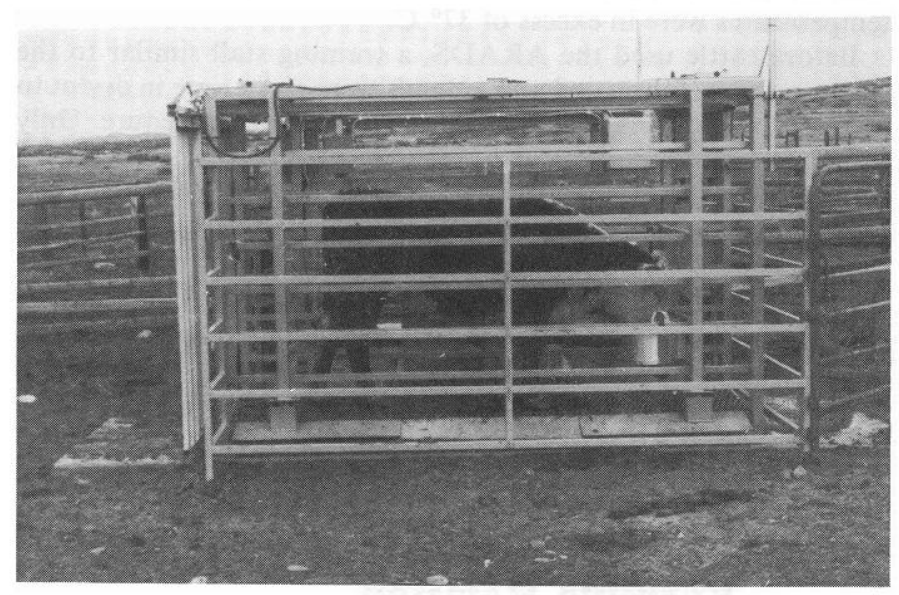

Fig. 3. Side view of a scale unit.

microprocessors to allow measurement of additional parameters (e.g., body temperature and electronic pedometers), and additional scale units or weather stations can be added to the present system.

A weather station is located centrally between the fall-winter and spring-summer study units. Weather variables measured include ambient air temperature, precipitation, wind direction, wind speed, solar radiation, humidity, barometric pressure, soil temperature, and snow or dust particle frequency and diameter. Weather data are recorded at 2-second intervals by a microprocessor at the weather station and averaged over each hour; these calculations can be changed under program control.

Each scale unit and the weather station are equipped with a variable-speed RF modem and a 5-watt radio for transmission of data to the computer located approximately $10 \mathrm{~km}$ from each study site. The radio signal is sent from the data generating units through a radio relay located on a high point to the main computer located in a laboratory building (Fig. 1). Communication is bidi- 


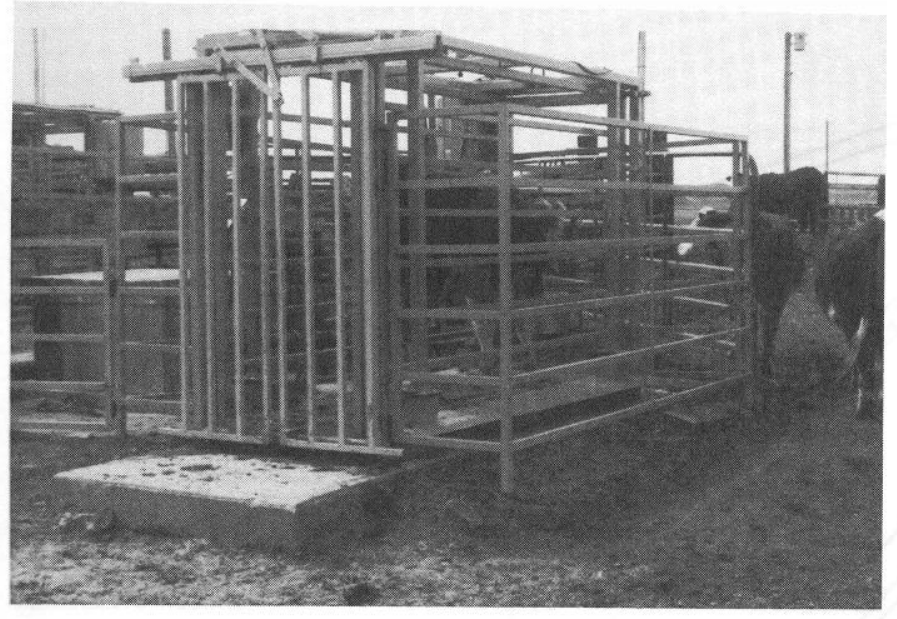

Fig. 4. Oblique view of a scale unit.

rectional and control settings can be changed from the central computer. The central computer accesses each data generating unit as required to generate data files for analysis.

\section{Utilization of ARADS}

ARADS was installed during the fall and winter of 1985-86, and ARADS has received preliminary testing under harsh winter conditions and was used for field research during the summer. All systems performed satisfactorily during winter and summer use. During the winter use, ground snow was present and ambient air temperatures dropped below $-30^{\circ} \mathrm{C}$, and during the summer, air temperatures were in excess of $37^{\circ} \mathrm{C}$.

Before cattle used the ARADS, a training stall similar to the scale units was fabricated and animals were given time in drylot to acquaint themselves with the stall and drinking procedure. Only
2-3 days were required for animals to make the transition from the training stall to the scale units in the field. An occasional animal chose to eat snow rather than drink in the scale stall; however, once an animal drank in the stall, the procedure became routine and did not appear to be a problem.

One scale unit has served up to 40 animals without difficulty. In winter studies, there is little tendency for more than one animal to attempt to enter the scale unit simultaneously. In summer, however, the air-powered gates are essential to ensure individual animal weights.

Our preliminary findings show that ARADS will greatly enhance data collection at the USDA-ARS Research Laboratory at Miles City and will provide a significant technological means of improving range-animal research. ARADS enables researchers to conduct experiments employing frequent individual animal statistics as well as plot-to-plot comparison. Plant-animal-weather interactions can be studied in detail without disrupting individual animal activities. Such data should be useful for systems analysis and modeling efforts.

\section{Literature Cited}

Adams., D.C. 1985. Effect of time of supplementation on performance, forage intake and grazing behavior of yearling beef steers grazing Russian wild ryegrass in the fall. J. Anim. Sci. 61:1037-1042.

Adams, D.C., T.C. Nelsen, W.L. Reynolds, and B.W. Knapp. 1986. Winter grazing activity and forage intake of range cows in the Northern Great Plains. J. Anim. Sci. 62:1240-1246.

Anderson, D.M. J.A. Landt and P.H. Salazer. 1981. Electronic weighing, identification and subdermal body temperature sensing of range livestock. P. 313-328. In: J.L. Wheeler and R.D. Muchrie (eds.). Forage evaluation: concepts and techniques. CSIRO and Ann. Forage and Grassl. Counc., Melbourne, Australia.

Cogswell, C., and L.D. Kamstra. 1976. The state of maturity and its effects upon the chemical composition of 4 native range species. J. Range Manage. 29:460-463.

Martin, S.C., K.K. Barnes, and L. Bashford. 1967. A step toward automatic weighing of range cattle. J. Range Manage. 20:91-94.

\section{Formula Revision}

In the manuscript, "Field Evaluation of Five Grasses Grown on Saline Soils," published in the September 1986 issue of Journal of Range Management 39(5) in Col. 1, Para. 3, p. 388, we presented the formula DE $(\mathrm{MJ} / \mathrm{kg})=$ 0.1233 crude protein +0.1705 IVOMD. The formula used in making the calculation was $\mathrm{DE}(\mathrm{MJ} / \mathrm{kg})=0.1233 \mathrm{CP}+$ $0.1705 \mathrm{D}$-value (In vitro) - 0.285. Calculations appearing in the article were made correctly but the wrong formula was presented by the authors. The authors appreciate Dr. Larry White, ARS, Woodward, OK, for bringing this to our attention and Dr. Smith, Journal of Range Management for publishing this correction. 